\title{
2D PET SENSITIVITY EVALUATION USING A 20CM DIAMETER PHANTOM
}

\author{
M Monjur Ahasan \\ Atomic Energy Centre, Ramna, Dhaka, Bangladesh \\ email: monjur_ahasan@yahoo.co.uk
}

\begin{abstract}
A prototype small ring camera 'miniPET' with a FOV of $20 \mathrm{~cm}$ and as a 16crystal-ring tomograph was constructed by reconfiguring components from a standard medical ECAT PET. Alternate detector modules from the original standard system were used to make the miniPET with a diameter $50 \%$ of the original. After calibrating the camera, the sensitivity of the system was measured using a $20 \mathrm{~cm}$ diameter $68-\mathrm{Ge}$ cylindrical phantom. The aim of the study is to investigate the coincidence events detection performance (sensitivity) of the camera in 2D mode (ring difference $\leq 3$ ) but without septa using a large size phantom in respect to the camera FOV. Results indicate that the sensitivity measured using the phantom $(6.2 \mathrm{cps} / \mathrm{kBq})$ is approximately $30 \%$ lower than that measured using a line source of $3 \mathrm{~mm}$ diameter. The difference can be attributed to attenuation in the phantom.
\end{abstract}

Key words: PET/CT, Sensitivity, 68-Ge Cylindrical Phantom, Cyclotron.

\section{INTRODUCTION}

Positron emission tomography (PET) is a powerful medical imaging technique [1,2]. The latest generation of PET scanners incorporate a computed tomography (CT) scanner to provide accurate anatomical images, and the integrated system is known as PET/CT, which has been used in many clinical applications [3-5]. The more difficult part is the use of a PET/CT system which requires cyclotron produced positron emitting sources such as 18-F, 15-O, 11-C etc.

Sensitivity of a PET camera represents its ability to detect true coincidence events 'true events' which is defined as the rate of true events per unit radioactivity. The true events are the events which are not attenuated in the attenuating media before hitting the PET detectors. The unit of sensitivity is usually expressed in $\mathrm{cps} / \mathrm{kBq}$ or sometimes in $\mathrm{cps} / \mathrm{kBq} / \mathrm{ml}$. For a ring scanner imaging activity distributed uniformly along the central axis, the true event rate in the PET imaging process is described by the following formula [Equation 1] [6, 7].

$$
\mathrm{T} \propto \frac{\mathrm{Z}^{2}}{\mathrm{D}}
$$

where $\mathrm{Z}$ is the axial length of the active acquisition volume and $\mathrm{D}$ is the scanner diameter.

The sensitivity for a PET system is usually measured with a low activity source in the absence of attenuating media where the randomness and dead time contribution are nearly zero. The sensitivity of such a system has traditionally been measured using a distributed source, which is relatively longlived tracer (such as 18-F), in water [8]. The measurement was then done without doing any scattered and attenuation correction. Later on, many PET scientists found the contribution of Compton scattered gamma rays in the scanner field of view (FOV), which is 2 to 5 times greater when the scanner operated without septa (lead or tungsten materials which separated the PET crystal rings). As the huge amount of scattered events (20-50\% or more) contributes in 3D PET, so a scatter correction must be 
considered in the study. The goal of the present work is to find the detection performance of the camera in $2 \mathrm{D}$ mode (ring difference $\leq 3$ ) but without septa using a large size phantom in respect to the camera field of view (FOV).

\section{MATERIALS AND METHOD}

A prototype small ring camera 'miniPET' with a FOV of $20 \mathrm{~cm}$ was constructed by reconfiguring components from a standard medical ECAT PET. Alternate detector modules (even numbered modules) from the original standard system were used to make the miniPET with a diameter of 50\% of the original. The physical shape of the new geometry was the same as the original standard system, but the size was reduced by about half. The camera was designed as a 16-rings tomograph having 4096 individual crystal detectors. After calibrating the camera, the sensitivity of the system was measured using a 68-Ge cylindrical phantom (CTI Molecular Imaging, Serial no. 1804), $25 \mathrm{~cm}$ long and having a diameter of $20 \mathrm{~cm}$ with an activity of 7.7MBq [Figure 1].

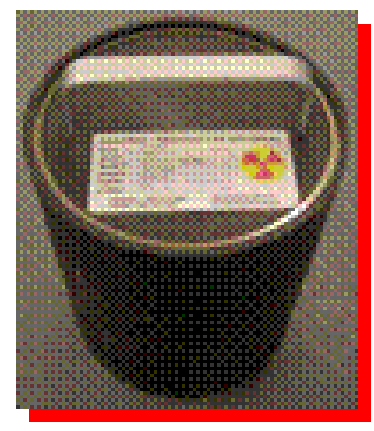

Fig.1: The 68-Ge cylindrical phantom (CTI Molecular Imaging)

In 2D PET mode (ring difference $\leq 3$ ) but without septa, the coincidence events were acquired for 600 seconds by positioning the phantom at the centre of the camera FOV. This data was used to analyze the sensitivity in order to measure the scanner sensitivity using a large size phantom in respect to the scanner FOV. The lower and upper energy discriminator levels were set at 250 and $850 \mathrm{keV}$, respectively. The width of the coincidence time window was set at $12 \mathrm{~ns}$.

\section{RESULTS}

The sensitivity was measured using the data from a $20 \mathrm{~cm}$ diameter uniform cylindrical phantom by summing counts from all planes [Table-1].

Table-1: Image plane counts for 600sec from a $68-$ Ge cylindrical phantom with an activity of 7.7MBq positioned at the centre of the PET system.

\begin{tabular}{|c|c|c|c|c|c|c|c|c|c|}
\hline $\begin{array}{c}\text { No. of } \\
\text { Image } \\
\text { Plane }\end{array}$ & $\begin{array}{c}\text { Plane } \\
\text { Counts }\end{array}$ & $\begin{array}{c}\text { No. of } \\
\text { Image } \\
\text { Plane }\end{array}$ & $\begin{array}{c}\text { Plane } \\
\text { Counts }\end{array}$ & $\begin{array}{c}\text { No. of } \\
\text { Image } \\
\text { Plane }\end{array}$ & $\begin{array}{c}\text { Plane } \\
\text { Counts }\end{array}$ & $\begin{array}{c}\text { No. of } \\
\text { Image } \\
\text { Plane }\end{array}$ & $\begin{array}{c}\text { Plane } \\
\text { Counts }\end{array}$ & $\begin{array}{c}\text { No. of } \\
\text { Image } \\
\text { Plane }\end{array}$ & $\begin{array}{c}\text { Plane } \\
\text { Counts }\end{array}$ \\
\hline 1 & 125723 & 8 & 563786 & 15 & 458801 & 22 & 614482 & 29 & 471919 \\
\hline 2 & 259322 & 9 & 482268 & 16 & 592229 & 23 & 506084 & 30 & 339120 \\
\hline 3 & 431133 & 10 & 519776 & 17 & 527137 & 24 & 604319 & 31 & 186889 \\
\hline 4 & 551554 & 11 & 438199 & 18 & 592569 & 25 & 524051 & & \\
\hline 5 & 446040 & 12 & 551505 & 19 & 489777 & 26 & 600761 & & \\
\hline 6 & 597197 & 13 & 447284 & 20 & 592897 & 27 & 496624 & & \\
\hline 7 & 457353 & 14 & 565675 & 21 & 480720 & 28 & 616878 & & \\
\hline
\end{tabular}


The sum of all plane counts, $\sum_{\mathrm{i}=1}^{31} \mathrm{P}_{\mathrm{i}}=15132072$

The activity of the source was $7.7 \mathrm{MBq}$, of which $4.1 \mathrm{MBq}$ was in the FOV. The active volume of the source is $6189 \mathrm{ml}$, so the specific activity was $1.24 \mathrm{kBq} / \mathrm{ml}$.

The sensitivity for the cylindrical phantom at the centre was therefore measured as $6.2 \pm 0.3 \mathrm{cps} / \mathrm{kBq}$ (based on the total activity in the FOV) or $20 \pm 1 \mathrm{cps} /(\mathrm{Bq} / \mathrm{ml})$.

\section{DISCUSSION}

The newly designed prototype small ring PET camera under this experiment was operated in 2D mode (ring difference $\leq 3$ ) but without septa so that the camera produced 31 image planes. Among these, it was 16 direct planes as it was a 16-rings PET camera and the remaining 15 planes were cross planes. In Table-1, it is found that the direct plane counts are slightly lower than the counts observed in cross plane because of more ring combination in cross plane. On the whole, the relative sensitivities correspond closely to the numbers of detector ring combinations contributing to each plane [9]. In general, direct planes contain 3 combinations while cross planes contain 4 combinations. The end planes ( 1 and 31 ) contain only a single combination so that the sensitivity observed in planes 1 and 31 is anomalously low. In the previous study [10], it is observed that the absolute sensitivity values of $12.1 \mathrm{cps} / \mathrm{kBq}$ (cross plane) and $8.8 \mathrm{cps} / \mathrm{kBq}$ (direct plane) are slightly lower (by approximately $12 \%$ in each case) than the values calculated using the simple geometrical model and assuming a detector efficiency of 0.5 [11].

The sensitivity measured using the $20 \mathrm{~cm}$ diameter cylinder $(6.2 \mathrm{cps} / \mathrm{kBq})$ was approximately $30 \%$ lower than that measured using a line source of $3 \mathrm{~mm}$ diameter. The difference can be attributed to attenuation in the phantom. In traversing $20 \mathrm{~cm}$ water, $511 \mathrm{keV} \gamma$-rays are attenuated by almost a factor 0.15 . In order to account for the observed sensitivity, many of the scattered $\gamma$-rays must be included in the measured count rate.

The total sensitivity for the original ECAT 951, measured in 2D using a $20 \mathrm{~cm}$ diameter cylindrical source, was quoted as $4.07 \mathrm{cps} /(\mathrm{Bq} / \mathrm{ml})$ [12]. The miniPET sensitivity of $20 \pm 1 \mathrm{cps} /(\mathrm{Bq} / \mathrm{ml})$ is approximately 5 times higher. Equation 1 states that the sensitivity for a ring scanner is proportional to $\mathrm{Z}^{2} / \mathrm{D}$, where $\mathrm{Z}$ is the axial length and $\mathrm{D}$ the ring diameter. Compared to the original ECAT 951, miniPET has the same $Z$ but $D$ reduced by a factor of 2 , so that one would expect the sensitivity to be doubled. However, this comparison overlooks the fact that miniPET was operated without septa, which significantly increases the sensitivity.

A study [13] measured the sensitivity of a $50 \mathrm{~cm}$ diameter scanner using a $10 \mathrm{~cm}$ diameter cylindrical scanner, and obtained the results $2.28 \mathrm{cps} /(\mathrm{Bq} / \mathrm{ml})$ in high sensitivity $2 \mathrm{D}$ mode and $22.8 \mathrm{cps} /(\mathrm{Bq} / \mathrm{ml})$ in $3 \mathrm{D}$ mode. Allowing for the difference in phantom diameter (so that our measurements were performed with four times the active volume per unit axial length) our result of $20 \pm 1 \mathrm{cps} /(\mathrm{Bq} / \mathrm{ml})$ using a $20 \mathrm{~cm}$ diameter cylinder is intermediate between their results, as expected since the miniPET uses $2 \mathrm{D}$ acquisition but without septa.

\section{CONCLUSION}

The sensitivity of the miniPET measured using a $20 \mathrm{~cm}$ diameter cylinder was approximately $30 \%$ lower than that measured using a $3 \mathrm{~mm}$ diameter line source. The difference can be attributed to 
attenuation in the phantom. In traversing $20 \mathrm{~cm}$ water, $511 \mathrm{keV}$ gamma rays are attenuated by almost a factor 0.15. In order to account for the sensitivity, serious noise factor due to scattered events in PET must be included in the measured count rate.

\section{ACKNOWLEDGEMENT}

The authors express their thanks to Professor David J Parker, Director of the Birmingham University Positron Imaging Centre, UK for giving technical support in this work. The authors are also grateful to the Islamic Development Bank (IDB) for giving necessary financial support to continue this research.

\section{REFERENCES}

1. G. B. Shaha, Basics of PET Imaging: Physics, Chemistry, and Regulations, Springer, $2^{\text {nd }}$ Ed, Ch 3:41-68, 2010.

2. M. M. Ahasan and D. J. Parker, Design and initial performance evaluation of a prototype large ring PET scanner in "Advances in Electrical Engineering and Computational Science", S I Ao et al (Eds) Springer, 14: 161-172, 2009.

3. S. F. Barrington, M. N. Maisey and R. L. Wahl, (Eds), An atlas of Clinical Positron Emission Tomography. London: Arnold, 1-30, 2006.

4. S. Harkirat, S. S. Anand, I. K. Indrajit and A. K. Dash AK, Pictorial essay: PET/CT in tuberculosis, 18(2):141-147, 2008.

5. G. Tarantola, F. Zito and P. Gerundini, PET instrumentation and reconstruction algorithms in whole-body applications. J Nucl Med, 44:756-796, 2003.

6. K. Kouris, N. M. Spyrou, D. F. Jackson, Imaging with ionisation radiations. 1982 ed. Surrey: Surrey Univ Press, 1982.

7. S. F. Derenzo, Method of optimising side shielding in positron emission tomographs and for comparing detector materials. J Nucl Med, 21(10):971-977, 1980.

8. D. L. Bailey, Data acquisition and performance characterization in PET in "Positron Emission Tomography: Basic Science and Clinical Practice", Valk PE et al (Eds) Springer, 69-90, 2003.

9. M. M. Ahasan, Design and initial performance assessment of a prototype large ring PET scanner (macroPET), PhD thesis, The University of Birmingham, UK, 2009.

10. M. M. Ahasan, K. K. Akter, M. N. Khanam, R. Khatun, S. Akter and M. K. A. Khan, Sensitivity Analysis of a Positron Emission Tomography (PET) system. Journal of the Bangladesh Electronics Society (In press), 2012.

11. R. Sadrmomtaz, Modification of a medical PET scanner, PhD Thesis, The University of Birmingham, UK, 2005.

12. ECAT 951, 953 Service Manual. Siemens Medical System, Testing \& Diagnostics, 1985.

13. M. Watanabe, H. Okada, K. Shimizu, T. Ohmura, E. Yoshikawa, T. Kosugi, S. Mori and T. Yamashita, A high resolution animal PET scanner using compact PS-PMT detectors. Nucl. Sci. Symp (Conference Record IEEE), 2:1330-1334, 1996. 